\title{
Effects of Occupational Hazards on Pulmonary Health among Lathe Machine Workers: A Cross- Sectional Study in Tangail, Bangladesh
}

\author{
Farmin Sultana, Saiful Islam Rayhan, Sheikh Md. Imam Hossain, Taposh Sarkar, Radoanul Ahmade, \\ Md. Roman Mogal, Md. Asaduzzaman Sikder*
}

Department of Biochemistry and Molecular Biology, Mawlana Bhashani Science and Technology University, Tangail -1902, Bangladesh

*Corresponding Author: Dr. Md. Asaduzzaman Sikder; sikderma@mbstu.ac.bd ORCID: https://orcid.org/0000-0003-1297-5019

Received 08 October 2021;

Accepted 28 October 2021;

Published 01 November 2021

\begin{abstract}
Background: Occupational exposure to metal dust particles leads to irritation and initiation of inflammatory responses in the respiratory system that subsequently onsets lung diseases. Lathe machine workers have a greater risk of having lung diseases due to continuously conducting metal dust particles. This study aimed to explore the pulmonary health status of lathe machine workers. Methods: In this cross-sectional study, 80 individuals (lathe workers) were adopted from a different area of the Tangail district in Bangladesh. A questionnaire's survey was accomplished along with oximetry and spirometry. After that, blood was drawn for measuring Erythrocyte Sedimentation Rate (ESR), C-reactive protein (CRP), and Immunoglobulin E (IgE) test to the lung function abnormalities. Results: Among 80 lathe machine workers, $12 \%$ had breathing problems, $13.8 \%$ had coughing, $16.2 \%$ had to sneeze and $8.7 \%$ had a chest. In addition, spirometry results including, FVC, FEV1, FEV1\%, PEF, PEF\%, FEF25, FEF75, and FEF2575 were significantly lower in lathe workers compared to control. Moreover, higher levels of IgE $(264.93 \pm 141)$ and ESR $(11.5 \pm 4.77)$ were reported in lathe machine workers than in the control group. Not using protective masks and smoking were considered as risk factors for having respiratory diseases in lathe machine workers. Conclusion: This study concludes that exposure to metal dust particles can cause respiratory disease symptoms and lower pulmonary function in lathe machine workers. Furthermore, metal dust might also augment the blood IgE and ESR level.
\end{abstract}

Keywords: Occupational lung disease, Lathe machine workers, ESR, IgE, Oximetry, Respiratory dust, Spirometry.

\section{Introduction}

Even with safety standards issued by the Occupational Safety and Health Administration and other organizations, such as the National Institute of Occupational Safety and Health, occupational lung disease continues to be one of the most common work-related injuries ${ }^{[1]}$. American Thoracic Society statement on the occupational contribution to the burden of airway disease synthesized relevant data on this topic through $1999^{[2]}$. Since 2000, 14 separate studies have published values or provide data on chronic bronchitis or COPD due to work-related factors. The ATS review was concerned with the global burden of occupational exposures on airway disease, including asthma ${ }^{[2]}$. Another important early review was led by Oxman, focusing on industryspecific data, in which risk with dust-years of exposure ${ }^{[2]}$. The Japanese Ministry of Health, Labour, and welfare established that work environment management, work management, and health management were exposed workers ${ }^{[3]}$.

The ATS stated that "A careful review of the literature demonstrates that $15 \%$ of both asthma and COPD is likely to be work-related" ${ }^{[4]}$. Occupational asthma and COPD costs nearly $\$ 7$ billion annually in the United States ${ }^{[4]}$. Exposure to mineral dust especially in underground mining, such as gold, coal, and uranium mining has been shown to contribute to the development of COPD, the impact of poorly soluble low-toxicity particles also referred to as bio-persistent granular dust ${ }^{[5]}$. The severity of the disease is related to the material inhaled and the duration of the exposure. Even individuals who do not work in the industry can develop occupational disease through indirect exposure.

Deaths from work-related respiratory disease and malignancies for about $70 \%$ of all occupational disease mortality ${ }^{[6]}$. Mining or eliminating the use of cutting fluids effects on health and the environment since the mid-1990s, the workers may have 
respiratory and skin problems. Metalworking fluids constitute about $7 \%$ to $17 \%$ of the total machining costs ${ }^{[7]}$. Metalworking fluid (MWF) is used in industry and is a complex mix of mineral oils, synthetic fluids, additives, and preservatives that are Control of Substances Hazardous to Health Regulations 2002(COSHH) ${ }^{[8]}$. Subsequently, function impairment, an asymptomatic disease with interstitial fibrosis, and even progressive massive fibrosis have been secondary to iron exposure ${ }^{[9]}$. Occupational exposure to dust and chemical in lathe machine workers leads to irritation and initiation of inflammatory responses in the respiratory system that contribute to pulmonary homeostasis ${ }^{[10]}$. Some asbestos-related diseases (ARDs) such as malignant mesothelioma, lung cancer, laryngeal cancer, ovarian cancer, asbestosis, and pleural disease (pleural plaque and pleural thickening) ${ }^{[11]}$. Pulmonary siderosis known as Welder's lung is a rare occupational lung disease that occurs due to chronic inhalation of iron compounds and is commonly seen in arc-welders, oxyacetylene cutters, iron or miners, and silver polishers ${ }^{[12]}$. Additionally, nearly 519,100 deaths in 2016 result from exposure to silica, coal dust, and asbestos ${ }^{[13]}$. Lathe machine workers are exposed to particles rich in cobalt and tungsten carbide when treating cobalt alloy tools which are absorbed by the lungs and gastrointestinal tract ${ }^{[14]}$.

The lathe machine is a power-driven machine tool used to turn and cut metal in the lathe industry. Because of poor maintenance, most lathe machines in Bangladesh do not undergo standardized frequent accuracy testing. Indeed, the quality of machining is dependent on the machine's dynamic behavior throughout the operating process. For this reason, these types of machines have always been used widely and are not efficient ${ }^{[15]}$.

Biomarkers could improve our ability to monitor disease progression and in some cases provide insight into disease mechanisms ${ }^{[16]}$. Our present study attempted to investigate the relationship between blood parameters (IgE, ESR, and CRP) with lung function abnormalities. By performing spirometry, the lung function capacity of lathe machine workers was accessed.

At last, in every working sector work-related disease distress persons account for around $60 \%$ of all illnesses and $70 \%$ mortality from occupational disease. The occupational pulmonary disease scenario has influenced the lungs. Respiratory illness had been corresponding with age and now the dust particles are correlated with lung disorders. This study aims to evaluate the occurrence and risk factors of breathing problems, coughing, sneezing, chest tightness, allergic problem amongst different workers and determine who is more susceptible to pulmonary abnormalities.

\section{Materials and Methods}

\section{Participants and Study design}

This cross-sectional study was conducted among lathe machine workers and University students (control) selecting 80 individuals in each group from March 2020 to June 2021 in Tangail, Bangladesh. Approval was received from Institutional Ethics Committee. In the case of lung function, the Global Initiative on Obstructive Lung Disease(GOLD) definition was used for spirometric assessments ${ }^{[17]}$.

\section{Inclusion and Exclusion criteria}

Male workers (age ranged 15-74 years) who worked at least 1 year in lathe machines were dominated in this study. There are no female workers in this study.

\section{Questionnaire survey and collecting data}

All participants were approved to fill a detailed self-completed questionnaire about demographic information (age, BMI, and education), medical history, job history, and respiratory symptoms. Respiratory symptoms (including breathing, coughing, sneezing, chest tightness, and allergy) and mask using habits were recorded. The questionnaire was translated into Bengali. Collecting data were written in our paper assiduously.

\section{Oximetry}

After completing the questionnaire part, an oximetry test was performed. In this test, workers were requested to put one of their fingers in a pulse oximeter to acquire their heart rate and oxygen saturation level.

\section{Spirometry}

Spirometry test of all participants was completed by using a portable spirometer (SP 10 spirometer Contec. Medical System Co. Ltd., China). In our study, the spirometric test was performed in a standing position. The spirometer measured parameters were included, Forced Vital Capacity (FVC), forced expiratory volume in the first second (FEV1), FEV1/FVC ratio, PEF, and forced expiratory flow at $25 \%$ and $75 \%$ of vital capacity FEF 2575 .

\section{Blood sample collection and serum separation}

Blood samples were collected from workers who had abnormal lung function for ESR, CRP, and IgE tests. From every $5 \mathrm{ml}$, blood was drawn, $1.6 \mathrm{ml}$ was kept in the ESR test tube with Sodium Citrate, and $3.4 \mathrm{ml}$ to a serum test tube for CRP and $\operatorname{IgE}$ test. For the preparation of serum, blood was centrifuged (DSC-200 T, DIGISystem, Taiwan) at $1000 \mathrm{rpm}$ for $8 \mathrm{~min}$ at room temperature. Separated serum was stored at $-80^{\circ} \mathrm{C}$ with labeling in the refrigerator.

\section{Erythrocyte sedimentation rate (ESR) test}

Westergren's method was used in our study for the ESR test. In this process, blood was collected from the ESR tube into the Westergren tube (200 $\mathrm{mm}$ in length or $2.55 \mathrm{~mm}$ in diameter) and placed in the Westergren stand for $60 \mathrm{~min}$ at room temperature. After 1 hour the volume of the coagulated erythrocyte was seen. ESR values were measured in $\mathrm{mm} / \mathrm{hr}$.

\section{C- reactive protein (CRP) test}

C-reactive protein (CRP), an acute phase of protein is probably the most nonspecific marker of inflammation. In our research, the CRP Latex Kit (Biorex Diagnostics Limited, UK) was used by following the latex agglutination method. The latex suspension was linked with serum sample and undulated in a rotational machine at 200 rpm for $2 \mathrm{~min}$. The agglutination appearance indicates it or not $\mathrm{CRP}$ is present in the sample. After obtaining agglutination, serum was diluted 2, 4, 8, and 16 times. Then the CRP level was calculated. The total CRP levels were expressed as $\mathrm{mg} / \mathrm{L}$.

\section{Immunoglobulin E (IgE) test}

In general, elevated levels of IgE indicate an increased probability of an IgE-mediated hypersensitivity responsible for allergic reaction. IgE ELISA Kit (Biorex Diagnostics, UK) was used to measure total IgE levels quantitatively from a human serum sample. For microwell washing and absorbance, Thermo Scientific Well Washer and Thermo Scientific, Multiskan FC was used.

\section{Statistical analysis}

Data were analyzed using the Statistical Package SPSS (SPSS for windows version 20, IBM SPSS statistics Armonk, New York, USA). Data was revealed as mean $\pm \mathrm{SD}$ (standard deviation). The 
unconditional data were compared applying the Chi-square test on respiratory symptoms (smoking status, alcohol status, family history, and protective mask use) between lathe machine workers and control. Furthermore, a t-test was performed in spirometry, oximetry, and biochemical test parameters to determine the mean difference.

\section{Results}

\section{General characteristics of study subjects}

The general characteristics of the study subject are shown in table 1. The average age of lathe machine workers was $35.26 \pm 10.52$ years, and the control group was $22.68 \pm 2.08$ years. BMI was found higher in lathe workers $(22.72 \pm 2.68)$ compared to control $(22.34 \pm 1.69)$. $38.8 \%$ of lathe workers had no educational qualification, $22.5 \%$ had a primary school, $32.5 \%$ high school, $6.2 \%$ college, and $0 \%$ university education. However, $67.5 \%$ of lathe workers were not used to mask during their working time.

\section{Prevalence of respiratory symptoms}

Respiratory symptoms, including $12 \%$ Breathing problem, $13.8 \%$ Coughing, $16.2 \%$ Sneezing, $8.7 \%$ Chest tightness, and $37.5 \%$ Allergy symptoms were appeared in lathe workers (Table 2).

Table 1: General characteristic of study groups.

\begin{tabular}{|l|l|l|}
\hline Parameters & Lathe N $(\%)$ or Mean \pm SD & Control N $(\%)$ or Mean \pm SD \\
\hline Age & $35.26 \pm 10.52$ & $22.68 \pm 2.08$ \\
\hline BMI & $22.72 \pm 2.68$ & $22.34 \pm 1.69$ \\
\hline Education & & \\
\hline Illiterate & $31(38.8)$ & \\
\hline Primary school & $18(22.5)$ & \\
\hline High school & $26(32.5)$ & \\
\hline College & $5(6.2)$ & \\
\hline University & $0(0)$ & $80(100)$ \\
\hline Smoking status & & \\
\hline Never smoker & $20(25)$ & $54(67.5)$ \\
\hline Ex-smoker & $5(6.3)$ & $6(7.5)$ \\
\hline Current smoker & $55(68.7)$ & $20(25.5)$ \\
\hline Alcohol status & & \\
\hline Yes & $12(15)$ & $3(3.7)$ \\
\hline No & $68(85)$ & $77(96.3)$ \\
\hline Family history & & \\
\hline Yes & $5(6.3)$ & $12(15)$ \\
\hline No & $75(93.7)$ & $68(85)$ \\
\hline Protective mask use & & \\
\hline Yes & $26(32.5)$ & $54(67.5)$ \\
\hline No & $54(67.5)$ & $26(32.5)$ \\
\hline
\end{tabular}

Table 2: Prevalence of respiratory symptoms.

\begin{tabular}{|l|l|l|l|l|}
\hline Symptoms & Lathe N (\%) & Control N (\%) & $\boldsymbol{x}^{2}$ & $\boldsymbol{P}$-value \\
\hline Breathing & $8(12)$ & $8(10)$ & 1.127 & 0.288 \\
\hline Coughing & $11(13.8)$ & $9(11.3)$ & 1.617 & 0.204 \\
\hline Sneezing & $13(16.2)$ & $9(11.3)$ & 0.197 & 0.657 \\
\hline Chest tightness & $7(8.7)$ & $3(3.8)$ & 5.093 & 0.024 \\
\hline Allergy & $30(37.5)$ & $20(25)$ & 1.78 & 0.182 \\
\hline
\end{tabular}

$P$-value is significant at $<0.05$.

Table 3: Contrasts of spirometer and oximeter values between lathe and control.

\begin{tabular}{|l|l|l|l|l|}
\hline Parameters & Lathe $(M e a n \pm$ SD) & Control $($ Mean \pm SD $)$ & t-test & $P$-value \\
\hline FVC $(\mathbf{L})$ & $1.99 \pm 1.28$ & $3.29 \pm 0.342$ & -9.01 & 0.000 \\
\hline FVC $(\%)$ & $41.59 \pm 26.7$ & $78.01 \pm 9.92$ & -11.40 & 0.000 \\
\hline FEV1 (L) & $1.64 \pm 0.85$ & $3.10 \pm 0.30$ & -14.96 & 0.000 \\
\hline
\end{tabular}




\begin{tabular}{|l|l|l|l|l|}
\hline FEV1 (\%) & $41.05 \pm 21.8$ & $85.30 \pm 10.0$ & -16.94 & 0.000 \\
\hline PEF (L/s) & $3.54 \pm 2.09$ & $9.15 \pm 1.33$ & -21.86 & 0.000 \\
\hline PEF (\%) & $39.06 \pm 22.9$ & $108.7 \pm 17.8$ & -22.88 & 0.000 \\
\hline FEV1/FVC (\%) & $39.06 \pm 22.96$ & $94.51 \pm 4.01$ & -21.09 & 0.000 \\
\hline FEF25 (L/s) & $3.08 \pm 1.93$ & $7.49 \pm 1.37$ & -18.42 & 0.000 \\
\hline FEF75 (L/s) & $1.90 \pm 1.16$ & $2.57 \pm 0.59$ & -4.59 & 0.000 \\
\hline FEF2575 (L/s) & $2.54 \pm 1.52$ & $4.51 \pm 0.98$ & -10.14 & 0.000 \\
\hline Heart rate (BPM) & $85.01 \pm 11.83$ & $74.26 \pm 11.19$ & 3.21 & 0.003 \\
\hline Oxygen saturation (\%) & $97.78 \pm 1.44$ & $98.21 \pm 1.33$ & -1.43 & 0.321 \\
\hline
\end{tabular}

$P$-value is significant at $<0.05$.

Table 4: Comparison of blood parameters between lathe and control.

\begin{tabular}{|l|l|l|l|l|}
\hline Parameters & Lathe $($ Mean \pm SD) & Control $($ Mean \pm SD) & t-test & $P$-value \\
\hline IgE $(\mathbf{I U} / \mathbf{m l})$ & $244.93 \pm 141.01$ & $141.261 \pm 116.8$ & 2.453 & 0.01 \\
\hline ESR $(\mathbf{m m} / \mathbf{h})$ & $11.5 \pm 4.77$ & $8.78 \pm 3.94$ & 1.66 & 0.10 \\
\hline CRP $(\mathbf{m g} / \mathbf{l})$ & All<6 & All<6 & & \\
\hline
\end{tabular}

$P$-value is significant at $<0.05$

\section{Discussion}

The present study investigated the pulmonary health status with some blood biomarkers of lathe machine workers. This study showed that $67.5 \%$ of workers normally exposed to metal dust particles were not used to use protective masks compared to the $32.5 \%$ control group. Our present research was designed to explore the respiratory abnormalities in lathe machine workers and control using spirometry primarily. Workers with allergic symptoms showed a higher level of IgE.

High population attributed risk in the range of 5-25\% for occupational asthma and COPD from occupational exposures ${ }^{[18]}$. On the other hand, AIHW NDI data suggested that between 2000 and 2016, deaths from dust-related lung diseases were increased ${ }^{[19]}$. In Bangladesh, government and non-government organizations have been designing and implementing public health programs to combat NCDs such as diabetes and cardiovascular disease, no such public health program is prevailing directed to lung disease ${ }^{[20]}$.

The antecedent part of this study demonstrated their demographic features like the average age of lathe machine employees and control was $35.26 \pm 10.52$ and $22.68 \pm 2.08$ respectively. Recent international estimates have also shown that approximately $16 \%$ of adult asthma and $14 \%$ of COPD cases are associated with work-related exposures ${ }^{[19]}$. In our current study, the lathe machine workers experienced $12 \%$ breathing problems, $13.8 \%$ coughing, $16.2 \%$ sneezing, $8.7 \%$ chest tightness, and $37.5 \%$ allergy symptoms.

Spirometry was performed by the standards from the American Thoracic Society/European Respiratory Society ${ }^{[21]}$. A spirometer is used to assess lung function capacity and the existence of respiratory problems. Two factors were identified which are liable for lowering spirometer values in our study: a family history of respiratory problems and not wearing a mask. Lathe machine working site negatively influenced pulmonary function parameters like FVC, FEV1, FEV1/FVC\%, and PEF in lathe workers, resulting in an obstructive pattern of lung function that is associated with years of exposure and airborne dust and metal fragments in the worksite.

In our study latex technique was utilized to determine blood CRP, but no significant results were obtained. Increased CRP has been linked to a variety of causes in other research. Plasma C-reactive proteins are found in higher levels during COPD exacerbations and can be used to the severity of the disease ${ }^{[22]}$. Indeed CRP is considered to be a marker of systemic inflammation raised in COPD subjects compared to control in other studies ${ }^{[23]}$.
Pulmonary impairment and overall mortality are linked to a higher ESR. Compared to the control group a greater level of ESR. IgE has proved a key contributor to bronchial hyperreactivity development in asthmatics. In our current review, higher levels of IgE than in the control group have been discovered. The results of the T-test were significant for all control group workers.

\section{Conclusion}

The results analysis of this study suggests that occupational exposure to metal dust can cause respiratory disease. Exposure to dust particles causes of reduction in the pulmonary function parameters such as FVC, FVC\%, FEV1, FEV1\%, PEF, PEF\%, FEF25, FEF75, and FEF2575. This study terminated occupational metal dust particles also responsible for higher IgE and ESR levels.

\section{Acknowledgments}

The authors acknowledge and thank lathe machine workers for their invaluable support during this study. The authors are also grateful to the Department of Biochemistry and Molecular Biology (BMB), Mawlana Bhashani Science and Technology University (MBSTU), Tangail-1902, Bangladesh for providing laboratory support to carry out this research work.

\section{Author Contributions}

Conceptualization: Md. Asaduzzaman Sikder, Farmin Sultana Formal Analysis: Farmin Sultana, Md. Roman Mogal Investigation: Farmin Sultana, Saiful Islam Rayhan, Imam Hossain, Taposh Sarkar, Radoanul Ahmade

Supervision: Md. Asaduzzaman Sikder

Writing- Original Draft Preparation: Farmin Sultana, Md. Roman Mogal

Review \& Editing: Md. Asaduzzaman Sikder, Md. Roman Mogal

\section{Funding}

This research was supported through research funds of the department of BMB, MBSTU, Tangail-1902, Bangladesh [Project No.: MBSTU/BMB/2018-2019/A (B.Sc.)].

\section{Competing Interest}

The authors declare that they have no competing interest. 


\section{Ethics Approval}

This study was reviewed and approved by the ethical review committee of the department of BMB of MBSTU [Ethical approval number: MBSTU/BMB/TEST/2014/06 (3)]. All participants signed the written informed consents for participation and the use of data in research. All of the data were kept private and solely utilized for the purposes of this study.

\section{Data Availability Statement}

The data of this project was deposited in the Department of BMB, MBSTU, Tangail-1902, Bangladesh.

ORCID: Md. Asaduzzaman Sikder https://orcid.org/0000-00031297-5019

\section{References}

[1] A. Sirajuddin and J. P. Kanne, "Occupational Lung Disease," vol. 24, no. 4, pp. 310-320, 2009.

[2] P. D. Blanc and K. Torén, "STATE OF THE ART Edited by M. Chan-Yeung Occupation in chronic obstructive pulmonary disease and chronic bronchitis: an update," vol. 11, no. July 2006, pp. 251-257, 2007.

[3] T. Kasai, Y. Morimoto, Y. Natori, H. Kurosawa, and M. Nakano, "Update of occupational lung disease," no. April 2018, pp. 10-18, 2019, doi: 10.1002/13489585.12031.

[4] S. Accordini et al., "Incidence trends of airflow obstruction among European adults without asthma: a 20-year cohort study," pp. 1-9, 2020, doi: 10.1038/s41598-020-60478-5.

[5] I. Brüske, E. Thiering, J. Heinrich, K. Huster, and D. Nowak, "Biopersistent Granular Dust and Chronic Obstructive Pulmonary Disease: A Systematic Review and Meta- Analysis," vol. 8, no. 11, pp. 1-11, 2013, doi: 10.1371/journal.pone.0080977.

[6] S. Citation, The national academies press. 2008. doi: 10.17226/12171.

[7] B. Eker, B. Ekici, M. Kurt, and B. Bakır, "Sustainable machining of the magnesium alloy materials in the CNC lathe machine and optimization of the cutting conditions," vol. 20, no. 3, pp. 310-316, 2014.

[8] D. Fishwick et al., "Respiratory symptoms, immunology and organism identification in contaminated metalworking fluid workers. What you see is not what you get," pp. 238-241, 2005, doi: 10.1093/occmed/kqi049.

[9] D. Gothi, B. Satija, S. Kumar, and O. Kaur, "Interstitial Lung Disease due to Siderosis in a Lathe Machine Worker," Indian J. Chest Dis. Allied Sci., vol. 57, no. 1, pp. 35-37, 2015.

[10] D. K. Hosseini, V. M. Nejad, H. Sun, H. K. Hosseini, S. H. Adeli, and T. Wang, "Prevalence of respiratory symptoms and spirometric changes among non-smoker male wood workers," PLoS One, vol. 15, no. 3, 2020, doi: 10.1371/journal.pone.0224860.

[11] D. Kang et al., "Reconstruction of the Korean Asbestos Job Exposure Matrix," Saf. Health Work, vol. 12, no. 1, pp. 74-95, 2021, doi: 10.1016/j.shaw.2020.09.005.
[12] A. P. R, R. Krishnapriya, and R. Srinivasan, "Symptomatic Pulmonary Siderosis - A case report," vol. 4, no. 9, pp. 191-194, 2017.

[13] R. Ahmad, "Occupational Cement Dust Exposure and Inflammatory Nemesis: Bangladesh Relevance," no. June, 2021.

[14] R. F. Mizutani et al., "Hard metal lung disease : a case series," vol. 42, no. 6, pp. 447-452, 2016.

[15] A. A. D. Sarhan et al., "Improvement on a CNC Gantry Machine Structure Design for Higher Machining Speed Capability," no. November, pp. 9-14, 2015.

[16] N. A. Khan and M. K. Daga, "Novel and Emerging Blood Biomarkers in Chronic Obstructive Pulmonary Disease," vol. 2, no. 3, 2015.

[17] N. Govender, U. G. Lalloo, and R. N. Naidoo, "Occupational exposures and chronic obstructive pulmonary disease: a hospital based case e control study," pp. 597-601, doi: 10.1136/thx.2010.149468.

[18] X. Baur, P. Bakehe, and H. Vellguth, "Bronchial asthma and COPD due to irritants in the workplace - an evidence-based approach," no. Figure 1, pp. 1-31, 2012.

[19] "Occupational lung diseases in Australia 2006-2019."

[20] I. Sutradhar, M. Hasan, R. Das Gupta, and M. Sarker, "Prevalence and Risk Factors of Chronic Obstructive Pulmonary Disease in Prevalence and Risk Factors of Chronic Obstructive Pulmonary Disease in Bangladesh : A Systematic Review," no. January, 2019, doi: 10.7759/cureus.3970.

[21] I. Ojanguren, G. Moullec, J. Hobeika, and M. Miravitlles, "Clinical and inflammatory characteristics of Asthma-COPD overlap in workers with occupational asthma," pp. 1-11, 2018.

[22] J. M. Leung and D. D. S. Mph, "Biomarkers in airway diseases," vol. 20, no. 3, pp. 180-182, 2013.

[23] J. A. Dickens, B. E. Miller, L. D. Edwards, E. K. Silverman, and D. A. Lomas, "COPD association and repeatability of blood biomarkers in the ECLIPSE cohort," pp. 1-10, 2011.

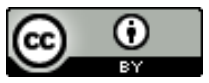

Open Access This article is licensed under a Creative Commons Attribution 4.0 International License, which permits use, sharing, adaptation, distribution and reproduction in any medium or format, as long as you give appropriate credit to the original author(s) and the source, provide a link to the Creative Commons license, and indicate if changes were made. The images or other third party material in this article are included in the article's Creative Commons license, unless indicated otherwise in a credit line to the material. If material is not included in the article's Creative Commons license and your intended use is not permitted by statutory regulation or exceeds the permitted use, you will need to obtain permission directly from the copyright holder. To view a copy of this license, visit https://creativecommons.org/licenses/by/4.0/.

(C) The Author(s) 2021 